\title{
Treatment of Persistent Rejection with Methotrexate in Stable Patients Submitted to Heart Transplantation
}

\author{
Fernando Bacal, Viviane Cordeiro Veiga, Alfredo Inácio Fiorelli, Giovanni Bellotti, \\ Edimar Alcides Bocchi, N oedir A ntonio Groppo Stolf, José A ntonio Franchini Ramires \\ São Paulo, SP - Brazil
}

\begin{abstract}
Objective - To evaluate the use of methotrexate for the treatment of recurrent rejection in heart transplant recipients.
\end{abstract}

Methods - We studied 6 patients submitted to heart transplantation that showed rejection grade $\geq 3 A$ (ISHLT) in two consecutives endomyocardial biopsy specimens. The dose was $11.26 \pm 3.75 \mathrm{mg} /$ week. The evaluated data were: ventricular function, endomyocardial biopsy, white cell count and number of rejection episodes before and after methotrexate administration.

Results - There was a reduction in the number of rejection episodes $(5.17 \pm 1.47$ before methotrexate; $2.33 \pm 1.75$ after 6 months and $3.17 \pm 2.99$ after 12 months of treatment, $p=0.0193$ ). The ventricular function was normal with ejection fraction of $76.5 \pm 4.80$ before and $75.6 \pm 4.59$ after methotrexate $(p=0.4859)$. One patient did not finish the treatment because he showed signs of rejection associated with severe pericardial effusion. Five patients had a reduction in the white cell count $(8,108 \pm 23.72$ before and $5650 \pm 1350$ after methotrexate, $p=0.0961)$. One pulmonary infection with complete resolution after antibiotic treatment was observed.

Conclusion-Methotrexate in low doses is an effective adjunct therapy in the treatment of recurrent rejection after heart transplantation.

Key words: heart transplantation, methotrexate, rejection

Instituto do Coração do Hospital das Clínicas - FMUSP

Mailing address: Fernando Bacal - Incor - Av. Dr. Enéas C. Aguiar, 44 05403-000 - São Paulo, SP - Brazil
The first heart transplant in Brazil was performed by Zerbini in 1968. Currently heart transplantation represents a well-established therapeutic option for end-stage heart failure that does not respond to medical treatment ${ }^{1}$.

During the last decade, cyclosporine and other immunosuppressant drugs produced better survival rates and quality of life for heart transplant recipients by reducing the frequency and intensity of rejection episodes ${ }^{2}$.

Despite the advances in immunosupressant therapy, acute graft rejection is still a major cause of morbidity and mortality in heart transplantation recipients. Acute rejection accounts for $20 \%$ and $25 \%$ of deaths in the early and late phases after transplantation, respectively ${ }^{3-10}$.

Methotrexate, a folic acid analog, was initially used for the treatment of some malignancies, severe psoriasis, and rheumatoid arthritis, and is now being used as an adjuvant immunosuppressant drug in cases of persistent rejection resistant to ordinary treatment ${ }^{3,8,11-13}$.

The objective of our study was to evaluate the use of low-dose methotrexate in out patients with persistent rejection grade $\geq 3 \mathrm{~A}$ (International Society of Heart and Lung Transplantation) ${ }^{14}$.

\section{Methods}

We studied six patients, five man $(83.3 \%)$ and one woman $(16.7 \%)$, mean age $35 \pm 19.5$ years, who undewent orthotopic heart transplantation in or Hospital and were followed by the same medical and multidisciplinary team. The diagnoses before heart transplantation were dilated cardiomyopathy (66.6\%), ischemic heart disease (16.7\%), and Chagas' disease (16.7\%). For baseline characteristics of these patients refer to table I.

All patients were clinically and hemodynamically stable, left ventricular function was normal, and two consecutive endomyocardial biopsies revealed rejection grade $\geq 3 \mathrm{~A}$ after oral corticosteroid pulse therapy. Endomyocardial biopsies were analyzed according to the International Society of Heart and Lung Transplantation (ISHLT) criteria ${ }^{14}$. 


\begin{tabular}{|c|c|c|c|c|c|}
\hline \# & Sex & Etiology & Age & Tx date & $\begin{array}{c}\mathrm{Bx} \\
\text { pre-treatment }\end{array}$ \\
\hline 1 & $\mathrm{~F}$ & Dilated & 59 & $28 / 12 / 96$ & $3 \mathrm{~A}$ \\
\hline 2 & M & Dilated & 9 & $16 / 9 / 93$ & $3 \mathrm{~A}$ \\
\hline 3 & M & Dilated & 37 & $26 / 6 / 85$ & $3 \mathrm{~A}$ \\
\hline 4 & M & Chagas & 16 & $22 / 3 / 93$ & $3 \mathrm{~A}$ \\
\hline 5 & M & Ischemic & 52 & $15 / 4 / 91$ & $3 \mathrm{~A}$ \\
\hline 6 & M & Dilated & 37 & $19 / 8 / 90$ & $3 \mathrm{~A}$ \\
\hline
\end{tabular}

Persistent rejection was defined as stability or worsening of rejection graduation ( $\geq 3 \mathrm{~A})$ in two consecutive biopsies 7 to 10 days apart. Patients received two courses of pulse therapy with oral prednisone $1 \mathrm{mg} / \mathrm{kg}$ per day during four days, followed by $0.2 \mathrm{mg} / \mathrm{kg}$ reduction every four days until the previous maintenance corticosteroid dose was achieved. If no improvement could be demonstrated, patients were selected to receive low-dose methotrexate in addition to the routine three-drug regimen. The immunosuppressant drug regimen is further described in table II. Routine posttransplantation evaluation for rejection comprises three endomyocardial biopsies performed in weeks 1 , 2 and 4 after transplantation. Beginning in week 4 (one month after transplantation) recipients underwent gallium67 isotope scintigraphy every two weeks up to the third month and thereafter monthly up to the sixth month. If clinical presentation or gallium scintigraphy were suggestive of rejection, patients then undewent endomyocardial biopsy for diagnostic confirmation. Treatment was only initiated after positive diagnostic findings.

The mean administered dose of methotrexate was $11.26 \pm 3.75 \mathrm{mg} /$ week for $96 \pm 14$ days, initiated $554 \pm 822$ days after transplantation.

The analyzed parameters were: ventricular function, endomyocardial biopsy, white blood cell count, and rejection episodes before and after methotrexate administration.

Statistical analysis was performed through paired Student's t test with a significance level of $p<0.05$.

\section{Results}

As shown in table III, methotrexate was administered $554 \pm 822$ days after transplantation, with a starting dose of $7.5 \pm 1.58 \mathrm{mg} /$ week, an average dose of $11.26 \pm 3.75 \mathrm{mg}$, for $96 \pm 14$ days. Patients had an average of $5.17 \pm 1.47$ episodes

\begin{tabular}{|ccccc|}
\hline \multicolumn{5}{|c|}{ Table II - Immunosuppressant therapy } \\
\hline$\#$ & $\begin{array}{c}\text { Azathioprine } \\
(\mathrm{mg} / \mathrm{kg} / \text { day })\end{array}$ & $\begin{array}{c}\text { Prednisone } \\
(\mathrm{mg} / \mathrm{kg} / \text { day })\end{array}$ & $\begin{array}{c}\text { Cyclosporine } \\
(\mathrm{mg} / \mathrm{kg} / \text { day })\end{array}$ & $\begin{array}{l}\text { level }(\mathrm{ng} / \mathrm{ml}) \\
\text { cyclosporine }\end{array}$ \\
\hline 1 & 2.86 & 0.28 & 4.3 & 178 \\
2 & 0.89 & 0.16 & 5.6 & 256 \\
3 & 1.25 & 0.16 & 4.0 & 170 \\
4 & 1.85 & 0.27 & 6.5 & 111 \\
5 & 2.35 & 0.17 & 4.0 & 123 \\
6 & 2.70 & 0.20 & 5.4 & 142 \\
\hline
\end{tabular}

of rejection before methotrexate, $2.33 \pm 1.75$ episodes after six months, and $3.17 \pm 2.99$ episodes after 12 months of treatment $(\mathrm{p}<0.0193)$ (fig. 1). Three patients $(50 \%)$ had no rejection after methotrexate interruption, 2 patients $(33.33 \%)$ had rejection grade $1 \mathrm{~A}$ and one patient was refractory to treatment persisting in rejection grade $3 \mathrm{~A}$.

Left ventricular function remained within normal limits. Left ventricular ejection fraction was $76.5 \pm 4.8 \%$ before and $75.6 \pm 4.59$ after treatment with methotrexate ( $<<0.4859)$ (fig. 2).

One patient did not complete the treatment because he had severe pericardial effusion on echocardiogram associated with signs of fatigue. The patient was admitted to the hospital and responded well to intravenous corticosteroid pulse therapy. In five patients a reduction occurred in white cell blood count from $8,108 \pm 2,372$ before to $5,650 \pm 1,350$ after treatment with methotrexate $(\mathrm{p}<0.0961)$ (fig. 3). We observed one episode of infection with white blood cell count elevation and signs of pulmonary infection. The patient's status improved after the administration of antibiotics in addition to methotrexate.

Survival rates were $100 \%$ in the first year and $83.33 \%$ by the end of the fifth year. One patient died 44 months after transplantation due to acute rejection. Survivors remained clinically stable.

\section{Discussion}

The folic acid analog methotrexate, initially used for the treatment of some malignancies, severe psoriasis, and rheumatoid arthritis, has been used as adjuvant medication to the routine three-drug immunosuppressant therapy (cyclosporine, azathioprine, prednisone) in cases of persistent rejection $3,8,10,12,13$.

The use of methotrexate was proposed in 1988 by Constanzo-Nordin et al, when they reported improvement in 9 out of 10 episodes of persistent rejection after methotrexate administration ${ }^{7,11,12}$.

Methotrexate's beneficial effects are due to its action in cellular and humoral immune response ${ }^{4,9,13}$, reducing B lymphocyte ability to secrete antibodies in response to specific and nonspecific stimulation. In addition, methotrexate interferes with cytokine production through interleukin secretion and reduces purine synthesis causing diminution in lymphocyte proliferation ${ }^{11,13,15,16}$.

Only one patient in the study did not reach the end of the proposed treatment because of fatigue, leg edema and severe pericardial effusion demonstrated by chest radiogram and echocardiogram. He was admitted to the hospital to receive corticoid pulse therapy.

Patients in this study were clinically and hemodynamically stable, and it is known that such patients have lower mortality. However, the question of whether or not to treat rejections in cases like these remains unsolved. There are clinical reports describing patients treated without pulse therapy for rejection grade 2 and also reports from groups that defend control of rejection at any price considering the re- 


\begin{tabular}{|c|c|c|c|c|c|c|c|}
\hline$\#$ & $\begin{array}{c}\text { MTX } \\
\text { Start (days) }\end{array}$ & $\begin{array}{l}\text { Rjct episodes } \\
\text { before MTX } \\
\quad(6 \mathrm{mo})\end{array}$ & $\begin{array}{l}\text { Rjct episodes } \\
\text { after MTX } \\
(6 \mathrm{mo})\end{array}$ & $\begin{array}{l}\text { Rjct grade } \\
\text { afterMTX }\end{array}$ & $\begin{array}{l}\text { Use of } \\
\text { MTX } \\
\text { (days) }\end{array}$ & $\begin{array}{c}\text { Initial dose } \\
\text { MTX } \\
\text { (mg/wk) }\end{array}$ & $\begin{array}{c}\text { Avrg dose } \\
\text { MTX } \\
\text { (mg/wk) }\end{array}$ \\
\hline 1 & 279 & 4 & 1 & $3^{\mathrm{A}}$ & 81 & 10.0 & 10.0 \\
\hline 2 & 137 & 5 & 0 & 0 & 77 & 7.5 & 7.5 \\
\hline 3 & 2227 & 5 & 2 & 1B & 105 & 7.5 & 14.4 \\
\hline 4 & 154 & 8 & 3 & 0 & 112 & 5.0 & 6.5 \\
\hline 5 & 211 & 4 & 3 & $1 \mathrm{~B}$ & 97 & 7.5 & 14.5 \\
\hline 6 & 320 & 5 & 5 & 0 & 104 & 7.5 & 14.5 \\
\hline
\end{tabular}

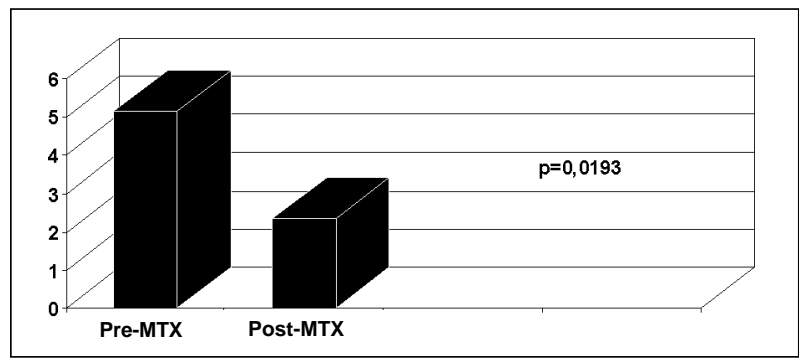

Fig. 1 -Episodes of rejection before and after methotrexate administration.

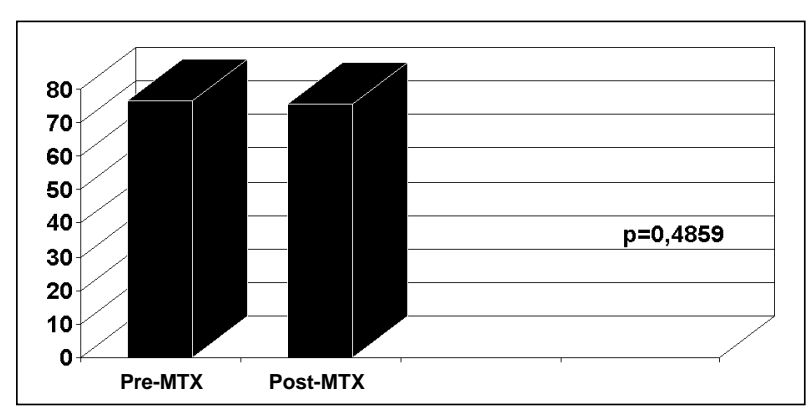

Fig. 2-Left ventricle ejection fraction before and after methotrexate.

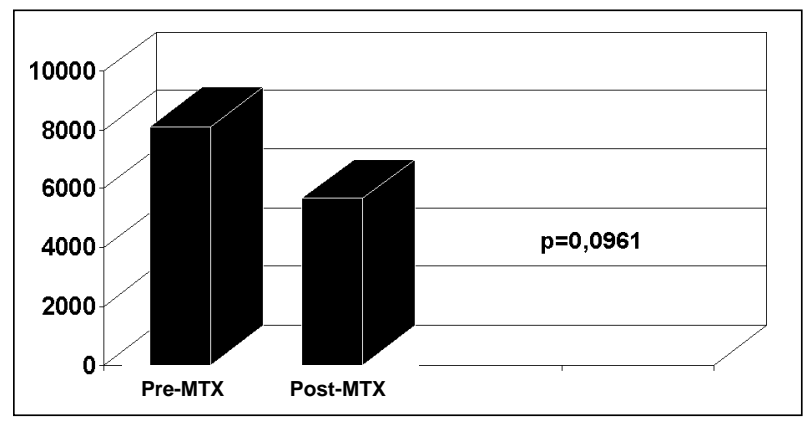

Fig. 3-White blood cell count before and after methotrexate.

duction of future complications, including graft vascular complications ${ }^{17-22}$.

Our group of patients had a particularly high incidence of rejection, especially considering the period of treatment initiation (after six months). In this period moderate rejection is rarely seen. However, it is well established that, even with the therapeutic arsenal currently available, a few patients will still experience rejection. Factors that might contribute for these findings are donor versus recipient histocompatibility, recipient of the female sex, drug interactions modifying serum levels of cyclosporine, sensitized recipients, and other causes yet to be understood ${ }^{6,7,12}$.

Infections are relatively common during methotrexate therapy. Constanzo-Nordin et al reported the case of a patient who died of Pseudomonas sp pneumonia after one intravenous dose of methotrexate $(150 \mathrm{mg})$. Possibly, the administered drug might predispose a patient to this complication ${ }^{3,4,12}$. In our group of patients, one subject had one episode of upper respiratory tract infection and received antibiotics with prompt resolution.

The initial dosage of methotrexate used in our study was smaller than the usual dose reported in the literature; nevertheless, it resulted in similar success rate, obtaining a reduction in moderate rejection episodes.

Some studies have reported severe leukopenia that probably interfered with the morbidity and mortality in their patients ${ }^{4,11,12}$. In our study, we found a reduction in white blood cell counts in five patients, but in none was there a need to interrupt the treatment. The synergistic myelosuppressor effect of azathioprine plus methotrexate might limit the use of this association: however, in clinical practice, several groups have maintained an azathioprine regimen, performing weekly blood cell counts, and suspending methotrexate administration if leukocyte count fell below 4,000 cells $/ \mathrm{mm}^{3}$. Using lower doses of methotrexate we found a mild reduction in white blood cell count, but it was no limitation for the treatment of our patients.

In conclusion, methotrexate is a safe and effective adjuvant immunosuppressant therapy, promoting reduction in rejection episodes, with mild side effects and is capable of preserving myocardial function.

Limitations of this study: Although the treatment was administered to a preselected group of patients, this was not a randomized clinical trial for it lacked a control group of patients using corticoid pulse therapy, and therefore we could not compare the efficacy and safety of each regimen.

The number of patients in our study was small because persistent rejection is less frequently seen with the currently available three-drug immunosuppressant regimen. Most cases of rejection subside after the first course of corticoid pulse therapy. 


\section{References}

1. Zerbini EJ. Transplante cardíaco. 25 anos de Transplante Cardíaco no Brasil 1993: 13-15.

2. Robbins RC, Barlow CW, Oyer PE, et al. Thirty years of cardiac transplantation at Stanford university. J Thorac Cardiovasc Surg 1999; 117: 939-51.

3. Bouchart F, Gundry SR, Van Schaack-Gonzales J, et al. Methotrexate as rescue/adjunctive immunotherapy in infant and adult heart transplantation. J Heart Lung Transplant 1993; 12: 427-33.

4. Bourge RC, Kirklin JK, White-Williams C, et al. Methotrexate pulse therapy in the treatment of recurrent acute heart rejection. J Heart Lung Transplant 1992; 11 : 1116-24.

5. Forni A, Faggian B, Chiominto B, Mazzucco A. Combined chronic administration of methotrexate and cyclosporine a following cardiac ongoing rejection. Transplant Proc 1998; 30: 1140-2.

6. Chan GL, Weinstein SS, Vijayanagar RR. Treatment of recalcitrant cardiac allograft rejection with methotrexate. Cardiac Transplant Team Clin Transplant 1995; 9: 106-14.

7. Hosenpud JD, Hershberger RE, Ratkovec RR, et al. Methotrexate for the treatment of patients with multiple episodes of acute cardiac allograft rejection. J Heart Lung Transplant 1992; 11: 739-45.

8. Taylor OD, Olsen SL, Ensley D, et al. Methotrexate for rejection prophylaxis after heart transplantation. J Heart Lung Transplant 1995; 14: 950-4.

9. Olsen SL, O'Connell JB, Bristow MR, et al. Methotrexate as an adjunct in the treatment of persistent mild cardiac allograft rejection. Transplantation 1990; 50: 773-5.

10. Ross HJ, Gullestad L, Pak J, Slauson S, Valantine HA, Hunt SA. Methotrexate or total lymphoid radiation for treatment of persistent or recurrent allograft cellula rejection: a comparative study. J Heart Lung Transplantation 1997; 16: 178-89.

11. ChinnockR,Emery J,Larsen R, etal. Methotrexate therapy for complex graft rejection in pediatric heart transplant recipients. J Heart Lung Transplant 1995; 14: 726-33.
12. Costanzo-Nordin MR, Grusk BB, Silver MA, et al. Reversal of recalcitrant cardiac allograft rejection with methotrexate. Circulation 1988; 78(suppIII): III-47-57.

13. Shaddy RE, Bullock EA, Tani LY, et al. Methotrexate therapy in pediatric heart transplantation as treatment of recurrent mild to moderate acute cellular rejection. J Heart Lung Transplant 1994; 13: 1009-13.

14. Billingham ME, Cary NRB, Hammond ME. A working formulation for the standardization of nomenclature in the diagnosis of heart and lung rejection: heart rejection study group. J Heart Lung Transplant 1990; 9: 587-92.

15. Rosenthal GJ, Weigand GW, Germolec DR. Supression of B cell function by methotrexate and trimetrexate: evidence of inhibition of purine biosynthesis as a major mechanism of action. J Immunol 1988; 141: 410-6.

16. Segal R, Mozes E, Yaron M. The effects of methotrexate on the production and activity of IL-1. Arthritis Rheum 1989; 32: 370-7.

17. Costanzo MR, Koch DM, Fisher SG, Heroux AL, Kao WG, Johnson MR. Effects os methotrexate on acute rejection and cardiac allograft vasculopathy in heart transplant recipients. J Heart Lung Transplant 1997; 16: 169-78.

18. Hosenpud JD, Bennett LE, Keck BM, Fiol B, Novick RJ. The registry of the International Society for Heart and Lung Transplantation: fourteenth official report1997. J Heart Lung Transplant 1997; 16: 691-712.

19. Weis M, von Scheidt W. Cardiac allograft vasculopathy: a review. Circulation 1997; 96: 2069-77.

20. Baan CC, Holweg CT, Niesters HG, et al. The nature of acute rejection is associated with development of graft vascular disease after clinical heart transplantation. J Heart Lung Transplant 1998; 17: 363-73.

21. Orbaek Andersen H. Heart allograft vascular disease: an obliterative vascular disease in transplanted hearts. Atherosclerosis 1999; 142: 243-63.

22. Libby $\mathrm{P}$, Tanaka $\mathrm{H}$. The pathogenesis of coronary arteriosclerosis ("chronic rejection") in transplanted hearts. Clin Transplant 1994; 8(Pt 2): 313-8. 